\title{
Antibacterial Activity of 2-Amino-1,4-naphthoquinone Derivatives against Gram-Positive and Gram-Negative Bacterial Strains and Their Interaction with Human Serum Albumin
}

\author{
Carla C. da Silva,,$^{\#, a}$ Otávio A. Chaves, ${ }^{\oplus \#, a, b}$ Rojane O. Paiva, ${ }^{\#, c}$ Gisela L. da Costa, ${ }^{c}$ \\ José Carlos Netto-Ferreira*,a,d and Aurea Echevarria ${ }^{*}, a$ \\ ${ }^{a}$ Departamento de Química Orgânica, Instituto de Química, \\ Universidade Federal Rural do Rio de Janeiro, 23890-000 Seropédica-RJ, Brazil \\ ${ }^{b}$ Instituto SENAI de Inovação em Química Verde, Rua Morais e Silva No. 53, Bloco 09, \\ 20271-030 Maracanã-RJ, Brazil \\ ${ }^{c}$ Laboratório de Taxonomia, Bioquímica e Bioprospecção em Fungos, Instituto Oswaldo Cruz, \\ Fundação Oswaldo Cruz, 21040-900 Rio de Janeiro-RJ, Brazil \\ ${ }^{d}$ Divisão de Metrologia Química, Instituto Nacional de Metrologia, Qualidade e Tecnologia, \\ 25250-020 Duque de Caxias-RJ, Brazil
}

\begin{abstract}
A series of 2-amino-1,4-naphthoquinone derivatives (NQA-NQF) was synthesized by alternative methods (ultrasonication and microwave irradiation), with yields ranging from 40 to $71 \%$, and without the need of further recrystallization. Each compound was evaluated against four Gram-positive (Bacillus subtilis, Enterococcus faecalis, Staphylococcus aureus and Bacillus cereus) and five Gram-negative (Escherichia coli, Klebsiella pneumoniae, Pseudomonas aeruginosa, Acinetobacter baumannii and Klebsiella pneumoniae positive $\beta$-lactamase) bacteria strains. The $\mathrm{NQF}$ was the most active amino-naphthoquinone derivative with minimum inhibitory concentration (MIC) of $31.2 \mu \mathrm{g} \mathrm{mL} \mathrm{m}^{-1}$ against $K$. pneumoniae positive $\beta$-lactamase (a common intestinal bacteria which can cause life-threatening infections). On the other hand, NQA and NQC showed good activity as a potential antibiotic for the bacteria strains assayed, except for $K$. pneumoniae. In addition, the affinity of these three most active compounds (NQA, NQC, and NQF) for human serum albumin (HSA) was evaluated employing multiple spectroscopic techniques (steady-state, time-resolved, and synchronous fluorescence, as well as circular dichroism), combined with theoretical calculations (molecular docking). The interaction HSA:2-amino-1,4-naphthoquinones occurs spontaneously and moderately inside the subdomain IIA (Sudlow's site I) via hydrogen bonding and van der Waals forces.
\end{abstract}

Keywords: 2-amino-1,4-naphthoquinones, antibacterial agent, human serum albumin, spectroscopy, molecular docking

\section{Introduction}

Naphthoquinones are natural aromatic compounds which can be found in various plant species, fungi, and bacteria. They are structurally related to naphthalene, with carbonyl groups being substituted at the 1,4 or 1,2 positions. The 1,4-naphthoquinones are known for their broad biological activity, including antitumor and antiproliferative, ${ }^{1,2}$ antimicrobial, ${ }^{3-5}$ and anti-inflammatory. ${ }^{6}$

*e-mail: jcnetto@ufrrj.br; echevarr@ufrrj.br

"These authors contributed equally to this work.
The biological activity of naphthoquinones is generally related to a redox process of the quinone system, which may lead to the formation of reactive oxygen species $(\mathrm{ROS}) .^{7} \mathrm{~A}$ proposed mechanism for this behavior may be due to the activation of futile cycling of the drug by the cytoplasmic two-electron reductase by the nicotinamide adenine dinucleotide phosphate oxidase $(\mathrm{NAD}(\mathrm{P}) \mathrm{H})$ :quinone oxidoreductase, also known as NQO1. This mechanism gives rise to highly reactive free radicals that are responsible for the cellular oxidative stress. ${ }^{8}$ The antimicrobial activity of naphthoquinone derivatives against various species of bacteria and fungi is well known..$^{9,10}$ 
In recent years, an increasing number of bacterial species have shown resistance to clinical antibiotics. Thus, the prevalence of strains of Staphylococcus aureus, Pseudomonas spp. and Streptococcus spp. resistant to conventional antibiotics has reached high levels in some hospitals. ${ }^{11-13}$ The development of new antimicrobial agents is considered an extremely important research area, and, in this sense, the use of naphthoquinone derivatives has attracted great attention due to their potential antibacterial action. ${ }^{14}$

Studies on molecular interactions of potential drugs with biomacromolecules (mainly transporter proteins) have been contributed significantly to a preliminary understanding of the biodistribution and availability of small compounds in biological fluids. According to this, human serum albumin (HSA, the most abundant protein in human plasma) has been used as a target to preliminary biodistribution evaluation, due to its ability to transport different classes of molecules and/or drugs in the human bloodstream. ${ }^{15-17}$ From the structural point of view, HSA is a heart-shaped protein containing 585 amino acid residues, which are arranged in three domains (I, II and III), with each domain being divided into two subdomains (A and B). The main internal fluorophore of HSA is the Trp-214 residue, located in the subdomain IIA. ${ }^{18}$ Generally, ligands which bind in the subdomain IIA (site I-negatively charged protein pocket) are compounds which present heterocyclic aromatic moieties, e.g., warfarin and azapropazone. This protein pocket is also known as Sudlow's site I. On the other hand, aromatic carboxylic acids like ibuprofen and aryl propionic acids generally bind in the subdomain IIIA, also known as Sudlow's site II. ${ }^{19,20}$

In the present work the six 2-alkylamino1,4-nahthoquinone derivatives shown in Figure 1, namely: 2-(benzylamino)-1,4-naphthoquinone (NQA), 2-(phenethylamino)-1,4-naphthoquinone (NQB), 2-[(2'-hydroxypropyl)amino]-1,4-naphthoquinone (NQC), 2,2"-[ethane-1,2-diyldi(amino)]-di-1,4-naphthoquinone (NQD), 2-[(3', 3' - diphenylpropyl)amino]1,4-naphthoquinone (NQE), and 2-(hydroxyethylamino)1,4-naphthoquinone (NQF), were synthesized. Importantly, of the six synthesized 2-alkylamino-1,4-nahthoquinone derivatives, four of them (NQB, NQC, NQD, and NQE) have not yet been described in the literature. The activity of these naphthoquinone derivatives was evaluated against four Gram-positive (Bacillus subtilis, Enterococcus faecalis, Staphylococcus aureus and Bacillus cereus) and five Gram-negative (Escherichia coli, Klebsiella pneumoniae, Pseudomonas aeruginosa, Acinetobacter baumannii and Klebsiella pneumoniae positive $\beta$-lactamase) bacteria strain. In addition, HSA affinity for the three most active compounds, i.e., NQA, NQC, and NQF, was assessed by multiple spectroscopic techniques (steady-state, time-resolved, and synchronous fluorescence, as well as circular dichroism) combined with theoretical calculations (molecular docking).

\section{Experimental}

\section{General information}

The melting points of the products were determined on a Gehaka PF 1500 Farma apparatus and were not corrected. Nuclear magnetic resonance $\left({ }^{1} \mathrm{H}\right.$ and distortionless enhancement by polarization transfer (DEPTQ) NMR) spectra were recorded on a Bruker Avance III spectrometer $\left({ }^{1} \mathrm{H}\right.$ in $500 \mathrm{MHz}$ and DEPTQ in $125 \mathrm{MHz}$ ) using tetramethylsilane (TMS) as the internal standard and chloroform- $d\left(\mathrm{CDCl}_{3}\right)$ as the solvent. Infrared spectra (FTIR) were recorded on a Bruker Vertex 70 spectrophotometer using a platinum attenuated total<smiles>O=C1C=C(NCc2ccccc2)C(=O)c2ccccc21</smiles><smiles>O=C1C=C(NCCc2ccccc2)C(=O)c2ccccc21</smiles><smiles>CC(O)CNC1=CC(=O)c2ccccc2C1=O</smiles><smiles>O=C1C=C(NCCNC2=CC(=O)c3ccccc3C2=O)C(=O)c2ccccc21</smiles>

Figure 1. Chemical structure for the 2-alkylamino-1,4-naphthoquinones: NQA-NQF.<smiles>O=C1C=C(NCCC(c2ccccc2)c2ccccc2)C(=O)c2ccccc21</smiles><smiles>O=C1C=C(NCCO)C(=O)c2ccccc21</smiles> 
reflection (ATR) accessory. Elemental analysis was performed on a PerkinElmer $2400 \mathrm{CHN}$ at the Laboratory of Environmental Science of the Universidade Estadual do Norte Fluminense (UENF). The microwave-assisted organic reactions were performed in a CEM Discovery System reactor.

Commercially available 1,4-naphthoquinone, phenylmethanamine, 2-phenylethanamine, 1-aminopropan2-ol, ethane-1,2-diamine, 3,3-diphenylpropan1-amine, 2-aminoethanol, $\mathrm{CDCl}_{3}$, silica gel $60 \mathrm{~F} 254$, $p$-iodonitrotetrazolium, chloramphenicol, HSA, ibuprofen, warfarin and phosphate buffer solution (PBS, $1.00 \times 10^{-2} \mathrm{M}$ phosphate buffer, $2.70 \times 10^{-3} \mathrm{M}$ potassium chloride and $1.37 \times 10^{-1} \mathrm{M}$ sodium chloride, at $\mathrm{pH}$ 7.4) were purchased from Sigma-Aldrich Chemical Company, St. Louis, MO, USA. Water used in all experiments was Millipore grade (Merck KGaA company, Darmstadt, Germany). The $n$-hexane, ethyl acetate, ethanol, dimethyl sulfoxide (DMSO), and acetonitrile (spectroscopic grade) were obtained from Vetec, Química Fina Ltda, Rio de Janeiro, Brazil.

General procedure for the synthesis of 2-amino1,4-naphthoquinones

Method A: about $1 \mathrm{mmol}$ of 1,4-naphthoquinone was solubilized in ethanol $(2.0 \mathrm{~mL})$ and submitted to an ultrasound bath for $10 \mathrm{~min}$. In the same flask, $1.5 \mathrm{mmol}$ of the adequate amine was added and the reaction mixture was sonicated for $1 \mathrm{~h}$ at room temperature. The product formation was monitored by thin-layer chromatography (TLC, silica gel 60 F254) using $n$-hexane:ethyl acetate (70:30) as eluent. After filtration using medium filter paper, the resulting solid was washed thoroughly with ethanol to give the corresponding 2-amino-1,4-naphthoquinone with high purity.

Method B: using the same stoichiometric conditions as method $\mathrm{A}$, the reaction mixture was submitted to a microwave reactor (CEM Discovery System) for $1 \mathrm{~h}$ at room temperature. Product formation was monitored by TLC and, after filtration, the obtained solid was washed intensively with ethanol.

\section{2-(Benzylamino)-1,4-naphthoquinone (NQA)}

Bright orange solid; yield $47 \%(\operatorname{method} \mathrm{A}), 71 \%$ (method B); mp $156{ }^{\circ} \mathrm{C}\left(154.5-155.5^{\circ} \mathrm{C}\right) ;^{21}$ FTIR (ATR) $v / \mathrm{cm}^{-1}$ 3061, 3032, $3002(\mathrm{~N}-\mathrm{H}), 1680,1592(\mathrm{C}=\mathrm{O})$, 2360, $2341(\mathrm{C}-\mathrm{N}), 1558,1440(\mathrm{C}=\mathrm{C}) ;{ }^{1} \mathrm{H}$ NMR $(500 \mathrm{MHz}$, $\left.\mathrm{CDCl}_{3}\right) \delta 8.12(\mathrm{~d}, 1 \mathrm{H}, J 5.0 \mathrm{~Hz}, \mathrm{H}-2), 7.75(\mathrm{t}, 1 \mathrm{H}, J 13.8 \mathrm{~Hz}$, H-3), 7.64 (t, 1H, J 13.8 Hz, H-4), 8.08 (d, 1H, J 5.0 Hz, H-5), 5.81 (s, 1H, H-7), 4.40 (d, 2H, J $1.3 \mathrm{~Hz}, \mathrm{H}-9), 7.35$ (m, 5H, H-12, H-13, H-14); ${ }^{13} \mathrm{C} \mathrm{NMR} \mathrm{(125} \mathrm{MHz,} \mathrm{CDCl}_{3}$ ) $\delta 181.9(\mathrm{C}-1), 133.6$ (C-1a), 127.7 (C-2), 132.1 (C-3), 134.8 (C-4), 126.3 (C-5), 130.5 (C-5a), 183.1 (C-6), 101.8 (C-7), 147.7 (C-8), 46.8 (C-9), 135.9 (C-10), 129.0 (C-11), 129.0 (C-12), 129.0 (C-13), 129.0 (C-14), 129.0 (C-15).

\section{2-(Phenethylamino)-1,4-naphthoquinone (NQB)}

Bright red solid; yield $32 \%$ (method A), $40 \%$ (method B); $\mathrm{mp} 145.1{ }^{\circ} \mathrm{C}$; FTIR (ATR) $v / \mathrm{cm}^{-1} 3060,3036$, $3031(\mathrm{~N}-\mathrm{H}), 2962,2919,2867(\mathrm{C}-\mathrm{H}), 2360,2341(\mathrm{C}-\mathrm{N})$, 1671, $1595(\mathrm{C}=\mathrm{O}), 1618,1567,1465(\mathrm{C}=\mathrm{C}) ;{ }^{1} \mathrm{H}$ NMR $\left(500 \mathrm{MHz}, \mathrm{CDCl}_{3}\right) \delta 8.12(\mathrm{sl}, 1 \mathrm{H}, \mathrm{H}-2), 7.74(\mathrm{sl}, 1 \mathrm{H}, \mathrm{H}-3)$, 7.63 (sl, 1H, H-4), 8.04 (sl, 1H, H-5), 5.80 (sl, 1H, H-7), 3.48 (sl, 2H, H-9), 3.01 (sl, 2H, H-10), 7.36 (m, 5H, H-12, $\mathrm{H}-13, \mathrm{H}-14, \mathrm{H}-15, \mathrm{H}-16) ;{ }^{13} \mathrm{C}$ NMR (125 MHz, $\mathrm{CDCl}_{3}$ ) $\delta 181.8$ (C-1), 133.6 (C-1a), 127.0 (C-2), 132.0 (C-3), 134.8 (C-4), 126.3 (C-5), 130.5 (C-5a), 183.0 (C-6), 101.0 (C-7), 147.7 (C-8), 43.7 (C-9), 34.3 (C-10), 137.8 (C-11), 128.9 (C-12 and C-15), 128.6 (C-13 and C-16); anal. calcd. for $\mathrm{C}_{18} \mathrm{H}_{15} \mathrm{NO}_{2}$ : C, 77.96; H, 5.45; N, 5.05, found: C, 78.05, $\mathrm{H}, 5.41, \mathrm{~N}, 5.12$.

\section{2-[(2'-Hydroxypropyl)amino]-1,4-naphthoquinone (NQC)}

Brown solid; yield 37\% (method A), 70\% (method B); mp $159^{\circ} \mathrm{C}$; FTIR (ATR) $\mathrm{v} / \mathrm{cm}^{-1} 3292(\mathrm{O}-\mathrm{H}), 2971,2936$, 2907, $2884(\mathrm{C}-\mathrm{H}), 2359,2342(\mathrm{C}-\mathrm{N}), 1682,1598(\mathrm{C}=\mathrm{O})$, 1623, 1564, $1470(\mathrm{C}=\mathrm{C}) ;{ }^{1} \mathrm{H}$ NMR $\left(500 \mathrm{MHz}, \mathrm{CDCl}_{3}\right)$ $\delta 8.08(\mathrm{~d}, 1 \mathrm{H}, J 7.5 \mathrm{~Hz}, \mathrm{H}-2), 7.72(\mathrm{t}, 1 \mathrm{H}, J 13.8 \mathrm{~Hz}, \mathrm{H}-3)$, 7.61 (t, 1H, J 13.8 Hz, H-4), 8.02 (d, 1H, J 7.5 Hz, H-5), 5.77 (s, 1H, H-7); ${ }^{13} \mathrm{C}$ NMR (125 MHz, $\left.\mathrm{CDCl}_{3}\right) \delta 181.7$ (C-1), 133.5 (C-1a), 126.3 (C-2), 132.1 (C-3), 134.8 (C-4), 126.2 (C-5), 130.5 (C-5a), 183.2 (C-6), 101.1 (C-7), 148.2 (C-8), 49.4 (C-9), 65.7 (C-10), 21.4 (C-11); anal. calcd. for $\mathrm{C}_{13} \mathrm{H}_{13} \mathrm{NO}_{3}$ : C, 67.52; H, 5.67; N, 6.06, found: C, 67.59, $\mathrm{H}, 5.61, \mathrm{~N}, 6.15$.

2,2"-[Ethane-1,2-diyldi(amino)]-di-1,4-naphthoquinone (NQD)

Brown solid; yield 30\% (method A), 71\% (method B); mp $144{ }^{\circ} \mathrm{C}$; FTIR (ATR) $v / \mathrm{cm}^{-1} 3052(\mathrm{~N}-\mathrm{H}), 2958,2936$ (C-H), 2359, $2342(\mathrm{C}-\mathrm{N}), 1682,1591(\mathrm{C}=\mathrm{O}), 1613,1561$, $1455(\mathrm{C}=\mathrm{C}) ;{ }^{1} \mathrm{H}$ NMR $\left(500 \mathrm{MHz}, \mathrm{CDCl}_{3}\right) \delta 8.11(\mathrm{~m}, 2 \mathrm{H}$, H-2, H-5), 7.57 (m, 2H, H-3, H-4), 5.65 (s, 1H, H-7), 3.75 (dd, 2H, J $2.5 \mathrm{~Hz}, \mathrm{H}-9)$; ${ }^{13} \mathrm{C}$ NMR (125 MHz, $\left.\mathrm{CDCl}_{3}\right) \delta$ 179.9 (C-1), 133.9 (C-1a), 127.3 (C-2), 131.6 (C-3), 131.7 (C-4), 126.6 (C-5), 133.4 (C-5a), 100.8 (C-7), 151.2 (C-8), 49.0 (C-9); anal. calcd. for $\mathrm{C}_{22} \mathrm{H}_{16} \mathrm{~N}_{2} \mathrm{O}_{4}$ : C, 70.96; $\mathrm{H}, 4.33$; $\mathrm{N}, 7.52$, found: C, 71.08, H, 4.12, N, 7.58.

2-[(3',3'-Diphenylpropyl)amino]-1,4-naphthoquinone (NQE)

Bright brown solid; yield 58\% (method A), 67\% (method B); $\mathrm{mp} 152{ }^{\circ} \mathrm{C}$; FTIR (ATR) $v / \mathrm{cm}^{-1} 3060,3025$, 
2974, 2885 (C-H), 2360, 2342 (C-N), 1676, 1591 (C=O), 1620, 1566, $1466(\mathrm{C}=\mathrm{C}) ;{ }^{1} \mathrm{H}$ NMR $\left(500 \mathrm{MHz}, \mathrm{CDCl}_{3}\right)$ $\delta 8.12(\mathrm{~d}, 1 \mathrm{H}, J 5.0 \mathrm{~Hz}, \mathrm{H}-2), 7.74$ (t, $1 \mathrm{H}, J 15.0 \mathrm{~Hz}, \mathrm{H}-3)$, 7.62 (t, 1H, J $15.0 \mathrm{~Hz}, \mathrm{H}-4), 8.08$ (d, 1H, J $5.0 \mathrm{~Hz}, \mathrm{H}-5$ ), 5.65 (s, 1H, H-7), 3.18 (q, 2H, H-9), 2.47 (q, 2H, H-10), 4.03 (t, 1H, H-11), 7.33 (m, 10H, H-13, H-14, H-15, H-16, $\mathrm{H}-17) ;{ }^{13} \mathrm{C}$ NMR (125 MHz, $\left.\mathrm{CDCl}_{3}\right) \delta 181.9(\mathrm{C}-1), 133.6$ (C-1a), 126.7 (C-2), 132.0 (C-3), 134.8 (C-4), 126.3 (C-5), 130.5 (C-5a), 182.9 (C-6), 101.0 (C-7), 147.8 (C-8), 41.2 (C-9), 33.8 (C-10), 48.9 (C-11), 143.6 (C-12), 128.8 (C-13 and $\mathrm{C}-17), 127.6$ (C-14 and $\mathrm{C}-16), 126.2$ (C-15); anal. calcd. for $\mathrm{C}_{25} \mathrm{H}_{21} \mathrm{NO}_{2}$ : C, 81.72; $\mathrm{H}, 5.76 ; \mathrm{N}, 3.81$, found: C, 81.82, H, 5.69, N, 3.89.

\section{2-[(2'-Hydroxyethyl)amino]-1,4-naphthoquinone (NQF)}

Bright brown solid; yield 20\% (method A), 40\% (method B); mp $156{ }^{\circ} \mathrm{C}\left(159.5-160.2{ }^{\circ} \mathrm{C}\right) ;{ }^{22}$ FTIR (ATR) $\mathrm{v} / \mathrm{cm}^{-1} 3341(\mathrm{O}-\mathrm{H}), 3058(\mathrm{~N}-\mathrm{H}), 2978,2935,2886(\mathrm{C}-\mathrm{H})$, 2360, $2342(\mathrm{C}-\mathrm{N}), 1674,1593(\mathrm{C}=\mathrm{O}), 1553,1467(\mathrm{C}=\mathrm{O})$; ${ }^{1} \mathrm{H} \mathrm{NMR}\left(500 \mathrm{MHz}, \mathrm{CDCl}_{3}\right) \delta 8.11(\mathrm{~d}, 1 \mathrm{H}, J 6.6 \mathrm{~Hz}, \mathrm{H}-8)$, 8.06 (d, 1H, J 6.6 Hz, H-5), 7.75 (t, 1H, J 7.7 Hz, H-6), $7.64(\mathrm{t}, 1 \mathrm{H}, J 7.7 \mathrm{~Hz}, \mathrm{H}-7), 6.26$ (sl, 1H), 5.79 (s, 1H, H-3), 3.95 (t, 2H, J $5.0 \mathrm{~Hz}, \mathrm{H}-11), 3.40$ (q, 2H, J $5.0 \mathrm{~Hz}, \mathrm{H}-10$ ); ${ }^{13} \mathrm{C}$ NMR $\left(125 \mathrm{MHz}, \mathrm{CDCl}_{3}\right) \delta 148.2(\mathrm{C}-2), 134.8(\mathrm{C}-6)$, 132.1 (C-7), 126.4 (C-8), 126.2 (C-5), 101.1 (C-3), 60.0 (C-11), 44.4 (C-10).

\section{Antibacterial assays}

The antibacterial assays were performed with Gram-positive (Bacillus subtilis INCQS 00001, Enterococcus faecalis CCBH 5069, Staphylococcus aureus INCQS 00015 and Bacillus cereus INCQS 00304) and Gram-negative (Escherichia coli CCBH 3860, Klebsiella pneumoniae INCQS 000532, Pseudomonas aeruginosa INCQS 00099, Acinetobacter baumannii CCBH 24360 and Klebsiella pneumoniae ATCC 70063 positive $\beta$-lactamase) as microorganisms. Bacteria were obtained from copies stored at $193 \mathrm{~K}$ and cultured in Mueller Hinton Agar (Oxioid, Basingtoke, UK) by $24 \mathrm{~h}$ at $310 \mathrm{~K}$. After, were standardized at $3.4 \times 10^{8}$ colony-forming unit $(\mathrm{CFU}) \mathrm{mL}^{-1}$ and diluted to $10^{7} \mathrm{CFU} \mathrm{mL}^{-1}$ for minimum inhibitory concentration (MIC) determination.

The MIC values (including the cutoff points to characterize the compounds in terms of their antimicrobial activity) were obtained by the microdilution broth method adapted from the literature. ${ }^{23}$ The assays were performed in 96-well culture microplates and the 2-amino-1,4-naphthoquinones were solubilized in DMSO:Mueller Hinton Broth (1:1) in the range of concentration 500-3.9 $\mu \mathrm{g} \mathrm{mL}^{-1}$. The chloramphenicol was used as a positive control in the range of $64-0.5 \mu \mathrm{g} \mathrm{mL} \mathrm{L}^{-1}$ and the mixture Muller Hinton Broth was evaluated to verify the possible influence on microorganism growth. The growth control was also used to verify the viability of bacteria, as well as a sterility test to control non-contamination by other microorganisms. The inoculum suspension $(5.0 \mu \mathrm{L}$ each well) was applied into microplates and incubated at $310 \mathrm{~K}$ overnight. After, $p$-iodonitrotetrazolium violet ( $p$-INT) in aqueous solution $(20 \mu \mathrm{L})$ was added and incubated at $310 \mathrm{~K}$ for $1-2 \mathrm{~h}$. The MIC values were defined as the lowest concentration of the compound that completely inhibits the bacterial growth observed by the permanence of the red coloring of the colorimetric reagent $\left(p\right.$-INT). ${ }^{24}$ All tests were performed in triplicate.

\section{Human serum albumin binding studies}

Spectroscopic analysis of the interaction HSA:NQA/NQC/ NQF

UV-Vis and steady-state fluorescence spectra were measured on a Jasco J-815 fluorimeter coupled with thermostated cuvette holder Jasco PFD-425S15F with $0.1{ }^{\circ} \mathrm{C}$ accuracy (Jasco Easton, MD, USA). All spectra were recorded with appropriate background corrections. The UV-Vis spectrum for NQA, NQC and NQF $\left(1.32 \times 10^{-5} \mathrm{M}\right)$ was recorded in the 200-600 nm range, in PBS, at $310 \mathrm{~K}$. For steady-state fluorescence measurements $(290-450 \mathrm{~nm}$ range and $\lambda_{\text {exc }}=280 \mathrm{~nm}$, at 296,303 and $310 \mathrm{~K}$ ), successive aliquots from a stock solution of NQA, NQC and NQF $\left(1.00 \times 10^{-3} \mathrm{M}\right.$, in acetonitrile) were added to $3.0 \mathrm{~mL}$ of HSA solution $\left(1.00 \times 10^{-5} \mathrm{M}\right.$, in PBS), leading to final ligand concentration of $0.17 ; 0.33 ; 0.50 ; 0.66 ; 0.83 ; 0.99$; 1.15 and $1.32 \times 10^{-5} \mathrm{M}$. The steady-state fluorescence data were analyzed at the maximum fluorescence emission wavelength $\left(\lambda_{\text {exc }}=340 \mathrm{~nm}\right)$.

Since NQA, NQC, and NQF showed significant absorption at the excitation and emission wavelengths (280 and $340 \mathrm{~nm}$, respectively, Figure S1 in the Supplementary Information (SI) section), the inner filter correction was applied to the steady-state fluorescence data, according to equation $1: 25$

$\mathrm{F}_{\text {cor }}=\mathrm{F}_{\mathrm{obs}} \times 10^{[(\mathrm{Aexc}+\mathrm{Aem}) / 2]}$

where $\mathrm{F}_{\text {cor }}$ and $\mathrm{F}_{\text {obs }}$ are the corrected and observed fluorescence intensity values. $\mathrm{A}_{\mathrm{exc}}$ and $\mathrm{A}_{\mathrm{em}}$ are the absorbance values for each ligand at excitation $(\lambda=280 \mathrm{~nm}: \varepsilon=20,355 ; 31,613$ and $61,913 \mathrm{~cm}^{-1} \mathrm{M}^{-1}$, for NQA, NQC and NQF, respectively in PBS) and emission wavelength $(\lambda=340: \varepsilon=2,955 ; 5,157$ and 7,332 $\mathrm{cm}^{-1} \mathrm{M}^{-1}$, for NQA, NQC and NQF, respectively in PBS). 
The following equations (equations 2-6) were applied to determine the binding parameters employing steady-state fluorescence emission spectroscopy:26,27

$$
\begin{aligned}
& \frac{\mathrm{F}_{0}}{\mathrm{~F}}=1+\mathrm{k}_{\mathrm{q}} \tau_{0}[\mathrm{Q}]=1+\mathrm{K}_{\mathrm{SV}}[\mathrm{Q}] \\
& \mathrm{k}_{\mathrm{q}}=\mathrm{K}_{\mathrm{sv}} / \tau_{\mathrm{o}} \\
& \frac{\mathrm{F}_{0}}{\mathrm{~F}_{0}-\mathrm{F}}=\frac{1}{f \mathrm{~K}_{\mathrm{n}}[\mathrm{Q}]}+\frac{1}{f} \\
& \ln \mathrm{K}_{\mathrm{a}}=-\Delta \mathrm{H}^{\circ} / \mathrm{RT}+\Delta \mathrm{S}^{\circ} / \mathrm{R} \\
& \Delta \mathrm{G}^{\circ}=\Delta \mathrm{H}^{\circ}-\mathrm{T} \Delta \mathrm{S}^{\circ}
\end{aligned}
$$

where, $\mathrm{F}_{0}$ and $\mathrm{F}$ are the steady-state fluorescence intensities of HSA in the absence and presence of each naphthoquinone derivative, respectively. The $\mathrm{K}_{\mathrm{sv}}$ and $\mathrm{k}_{\mathrm{q}}$ are the Stern-Volmer quenching constant and bimolecular quenching rate constant, respectively. The $[Q]$ and $\tau_{\mathrm{o}}$ are the NQA, NQC and NQF concentration and fluorescence lifetime of HSA without naphthoquinones $\left((5.90 \pm 0.10) \times 10^{-9} \mathrm{~s}\right.$, experimental data), respectively. The $\mathrm{K}_{\mathrm{a}}$ and $f$ are the modified Stern-Volmer binding constant and fraction of the initial fluorescence that is accessible to each naphthoquinone derivative ( $f$ ca. 1.00), respectively. The $\Delta \mathrm{H}^{\circ}, \Delta \mathrm{S}^{\circ}, \Delta \mathrm{G}^{\circ}$ are the enthalpy, entropy, and Gibbs free energy, respectively. The $\mathrm{R}$ and $\mathrm{T}$ are the gas constant $\left(\mathrm{R}=8.314 \times 10^{-3} \mathrm{~kJ} \mathrm{~mol}^{-1} \mathrm{~K}^{-1}\right)$ and temperature $(296,303$, and $310 \mathrm{~K}$ ), respectively.

Site marker competitive experiments were performed with warfarin (as site I marker) and ibuprofen (as site II marker). ${ }^{19}$ First, $3.0 \mathrm{~mL}$ of the $1.00 \times 10^{-5} \mathrm{M}$ HSA solution was added to a cuvette, followed by the addition of $1.00 \times 10^{-5} \mathrm{M}$ warfarin or ibuprofen solution (proportion HSA:site marker of 1:1) $\left(\lambda_{\text {exc }}=340 \mathrm{~nm}\right)$. Then, successive aliquots from a stock solution of NQA, NQC and NQF $\left(1.00 \times 10^{-3} \mathrm{M}\right.$, in acetonitrile) were added to HSA:site marker solution, leading to final ligand concentration of 0.17 ; $0.33 ; 0.50 ; 0.66 ; 0.83 ; 0.99 ; 1.15$ and $1.32 \times 10^{-5} \mathrm{M}$ at $296 \mathrm{~K}$.

Time-resolved fluorescence measurements were performed in a model FL920 CD fluorimeter from Edinburgh Instruments, equipped with an EPL laser $\left(\lambda_{\text {exc }}=280 \pm 10 \mathrm{~nm}\right.$; pulse of $850 \mathrm{ps}$ and energy of $1.8 \mu \mathrm{W}$ pulse $^{-1}$ ) at room temperature (ca. $298 \mathrm{~K}$ ). The fluorescence emission was monitored at $340 \mathrm{~nm}$. Timeresolved fluorescence decay for HSA $\left(1.00 \times 10^{-5} \mathrm{M}\right)$ $\left(\lambda_{\mathrm{em}}=340 \mathrm{~nm}\right)$ was obtained in the absence and in the presence of NQA, NQC or NQF $\left(1.32 \times 10^{-5} \mathrm{M}\right)$. This later concentration corresponds to the maximum ligand concentration used in the steady-state fluorescence measurement.

Synchronous fluorescence (SF) spectra were recorded in a spectrofluorimeter model Xe900 from Edinburgh
Instruments. The SF spectra were recorded for HSA $\left(1.00 \times 10^{-5} \mathrm{M}\right)$ without and in the presence of NQA, NQC and NQF (final concentration ranging from 0.17 to $\left.1.32 \times 10^{-5} \mathrm{M}\right)$, at room temperature (ca. $298 \mathrm{~K}$ ). Spectra were recorded in the $245-320 \mathrm{~nm}$ range by setting $\Delta \lambda=60 \mathrm{~nm}$ (for tryptophan) and $\Delta \lambda=15 \mathrm{~nm}$ (for tyrosine).

Circular dichroism (CD) spectra were measured in a spectropolarimeter Jasco J-815 employing a thermostatic cuvette holder Jasco PFD-425S15F with $0.1^{\circ} \mathrm{C}$ accuracy (Jasco Easton, MD, USA). All spectra were recorded with appropriate background corrections. The CD spectra were recorded in the 200-260 nm range for HSA solution $\left(1.00 \times 10^{-6} \mathrm{M}\right)$ without and in the presence of the maximum ligand concentration used in the steady state fluorescence measurements $\left(1.32 \times 10^{-5} \mathrm{M}\right)$, at $310 \mathrm{~K}$. $\mathrm{CD}$ results were expressed in terms of significant molar residual ellipticity (MRE) in $\mathrm{deg} \mathrm{cm}^{2} \mathrm{dmol}^{-1}$, according to equation $7:^{28}$

$\mathrm{MRE}=\theta / 10 \mathrm{nlC}_{\mathrm{p}}$

where $\theta, \mathrm{n}, 1$ and $\mathrm{C}_{\mathrm{p}}$ are the observed ellipticity (mdeg), number of amino acid residues (585 to HSA), ${ }^{18}$ length of the optical cuvette $(1.0 \mathrm{~cm})$ and molar concentration for HSA $\left(1.00 \times 10^{-6} \mathrm{M}\right)$, respectively. The loss on the helical structure of the protein due to ligand binding can also be quantitatively calculated as contents of free and combined HSA from MRE values at 208 and $222 \mathrm{~nm}$, using equations 8 and 9:28

$\alpha$-helix $(\%)=\left[\left(-\mathrm{MRE}_{208}-4000\right) /(33000-4000)\right]$ $\times 100$

$\alpha$-helix $(\%)=\left[\left(-\mathrm{MRE}_{222}-2340\right) / 30300\right] \times 100$

where, $\mathrm{MRE}_{208}$ and $\mathrm{MRE}_{222}$ are the significant molar residual ellipticities $\left(\mathrm{deg} \mathrm{cm}{ }^{2} \mathrm{dmol}^{-1}\right)$ at 208 and $222 \mathrm{~nm}$, respectively.

\section{Molecular docking analysis}

The crystallographic structure of HSA was obtained from the Protein Data Bank (PDB code 1N5U). ${ }^{18}$ The NQA, NQC, and NQF structures were built and energy-minimized with density functional theory (DFT), method Becke-3-Lee Yang Parr (B3LYP) with the standard 6-31G* basis set, available in the Spartan'14 program (Wavefunction, Inc., Irvine, CA, USA). ${ }^{29}$ Molecular docking was performed with GOLD 5.6 program (CCDC, Cambridge Crystallographic Data Centre), ${ }^{30}$ using the standard score function ChemPLP. The figure of the best docking pose for the largest docking 
score value was generated with the PyMOL program (DeLano Scientific LLC). ${ }^{31}$ Further details on molecular docking calculation were already reported in previous publications..$^{20,32}$

\section{Results and Discussion}

\section{Synthesis and antibacterial assays}

Two main methods have been described in the literature for the synthesis of 2-(alkylamino)-1,4-nahthoquinone derivatives: ${ }^{33}$ the first method involves a Michael 1,4-addition reaction between 1,4-naphthoquinone and the corresponding amino compound to afford the 2-amino-1,4-naphthoquinone. In the second, a nucleophilic substitution reaction between either a mono or a dihalogenated 1,4-naphthoquinone derivative and an amino compound is involved. It is important to note that both methods are inefficient, leading to low yields and laborious purification.

In the present work the synthesis of the 2-alkylamino1,4-naphthoquinones was performed using two alternative methods, such as ultrasound (method A) $)^{21,33}$ or microwave irradiation (method B). 1,4-Naphthoquinone and the appropriate amine were the starting material and ethanol was used as solvent. Among the two methods used, the one with the best results was the reaction with microwave irradiation. In this case, reasonable yields (40 to $71 \%$ ) were obtained for product formation. One of the major advantages in the present synthetic method is that there is not the necessity to get 2-chloro-naphthoquinone as intermediate (high reactive and toxicity). The chemical structure for the 2-alkylamino-1,4-naphthoquinones is shown in Figure 1, whereas the Fourier-transform infrared
(FTIR) and nuclear magnetic resonance (NMR ${ }^{1} \mathrm{H}$ and ${ }^{13} \mathrm{C}$ ) spectra related to their characterization are shown in Figures S2-S19 in the SI section.

The main ${ }^{1} \mathrm{H}$ NMR chemical shifts for the compounds NQA-NQF showed $\mathrm{H}-\mathrm{N}$ values in the range of $\delta$ 5.93-6.29. and $\delta$ 5.65-5.81 for the $\mathrm{H}-3$ associated to the quinone ring. The other ${ }^{1} \mathrm{H}$ signals showed values in full agreement with the literature. ${ }^{2}$ The main ${ }^{13} \mathrm{C}$ NMR chemical shifts were assigned to C-1 and C-4, in the range of $\delta$ 181.9-181.7 and 182.9-183.2, respectively, being in full accordance with the literature. ${ }^{2}$ In all cases, the chemical shift for the $\mathrm{C}-2$ linked to the amino moiety was observed in the characteristic range of $\delta$ 148.2-147.7. The chemical shift for C-3 was observed at $\delta$ 101.0-101.8, clearly indicating the presence of the double bond of the quinone ring. The full spectrometric and spectroscopic characterization for NQA-NQF is shown in Figures S2-S19 in the SI section.

Bacterial infections are among the leading causes of death worldwide, ${ }^{34}$ mainly due to increased resistance of certain bacteria to commercial antibiotics. ${ }^{14,35}$ The antibacterial effect related to naphthoquinones is well known, either from vegetal species or of synthetic origin, ${ }^{5,36}$ and it is very well known that amino derivatives of naphthoquinones have been listed as more bioactive compounds than other naphthoquinone derivatives. ${ }^{3,5,37}$ Based on this, the 2-amino-1,4-naphthoquinones (NQA-NQF) were assayed against B. subtilis, E. faecalis, S. aureus, B. cereus, E. coli, K. pneumoniae, P. aeruginosa, A. baumannii and $K$. pneumoniae positive $\beta$-lactamase using the broth microdilution test, ${ }^{23}$ with chloramphenicol as the positive control (Table 1). To verify the influence of the solvent used to solubilize the organic compounds, DMSO was assayed towards the bacteria strains and did not show any inhibition activity (Table 1).

Table 1. Minimum inhibitory concentration (MIC) values for the 2-(alkylamino substituted)-1,4-nahthoquinones (NQA-NQF) assayed against Grampositive and Gram-negative bacteria strains

\begin{tabular}{|c|c|c|c|c|c|c|c|c|c|}
\hline \multirow{3}{*}{ Compound } & \multicolumn{9}{|c|}{$\mathrm{MIC} /\left(\mu \mathrm{g} \mathrm{mL}^{-1}\right)$} \\
\hline & \multicolumn{4}{|c|}{ Gram-positive } & \multicolumn{5}{|c|}{ Gram-negative } \\
\hline & Bs & $S a$ & $E f$ & $B c$ & $P a$ & $E c$ & $A b$ & $K p 1$ & $K p 2$ \\
\hline NQA & 125 & 31.2 & 250 & 31.2 & 500 & 31.2 & 500 & $\mathrm{NI}$ & 250 \\
\hline NQB & NI & 62.5 & NI & 125 & NI & NI & 500 & NI & 250 \\
\hline NQC & 62.5 & 62.5 & 62.5 & 62.5 & 500 & 62.5 & 250 & NI & 62.5 \\
\hline NQD & NI & 500 & $\mathrm{NI}$ & NI & 500 & NI & 500 & NI & 500 \\
\hline NQE & NI & 250 & NI & NI & NI & NI & 500 & NI & NI \\
\hline NQF & 62.5 & 62.5 & 62.5 & 62.5 & 250 & 62.5 & 125 & 250 & 31.2 \\
\hline Chloramphenicol & 8 & 8 & 16 & 8 & 64 & 16 & NI & 64 & 16 \\
\hline DMSO & NI & NI & NI & NI & NI & NI & NI & NI & NI \\
\hline Growth & + & + & + & + & + & + & + & + & + \\
\hline Sterility & - & - & - & - & - & - & - & - & - \\
\hline
\end{tabular}

Bs: Bacillus subtilis; Sa: Staphylococcus aureus; Ef: Enterococcus faecalis; Bc: Bacillus cereus; Pa: Pseudomonas aeruginosa; Ec: Escherichia coli; Ab:Acinetobacter baumannii; Kp1: Klebsiella pneumoniae; Kp2: Klebsiella pneumoniae positive to $\beta$-lactamase; NI: not inhibited; DMSO: dimethyl sulfoxide. 
Synthetic naphthoquinone NQA was the most active naphthoquinone against two Gram-positive bacteria ( $S$. aureus and $B$. cereus), with minimum inhibitory concentration (MIC) values of $31.2 \mu \mathrm{g} \mathrm{mL}^{-1}$ in both cases. When comparing the structure of compounds NQA and NQB, there is clear evidence that the change from a phenylmethanamine group to a 2-phenylethanamine group in the naphthoquinone moiety leads to a decrease in the biological activity relative to Gram-positive bacteria (e.g., MIC values in the presence of NQB was 62.5 and $125 \mu \mathrm{g} \mathrm{mL}{ }^{-1}$ for $S$. aureus and B. cereus, respectively). On the other hand, the compounds NQC and NQF were more active than NQA for the Gram-positive bacteria B. subtilis and E. faecalis, with MIC value of $62.5 \mu \mathrm{g} \mathrm{mL}^{-1}$ in both cases. In this case, changing the 1-aminopropan-2-ol group to a 2-aminoethanol in the NQC and NQF structures, respectively, did not alter the inhibition profile towards Gram-positive bacteria, showing the same inhibition trend. These assayed compounds (except NQD, that did not show any significant antibacterial profile) were more active than some naphthoquinones derivatives described in the literature, e.g., 5-amino-8-hydroxy-1,4-naphthoquinone, ${ }^{38}$ 2,8-dihydroxy-5-amino-1,4-naphthoquinone, 5-amino6-bromo-8-hydroxy-1,4-naphthoquinone, and 5-amino8-hydroxy-1,4-naphthoquinone. ${ }^{39}$

Results from the antibacterial tests revealed that all compounds, except NQE, were active against $K$. pneumoniae positive $\beta$-lactamase, bacteria with high resistance to clinical antibiotics. For this case, the MIC values were observed in the range of 250 to $31.2 \mu \mathrm{g} \mathrm{mL}^{-1}$ and NQF was the most active compound $\left(\mathrm{MIC}=31.2 \mu \mathrm{g} \mathrm{mL}^{-1}\right)$. Probably, the biological activity of the synthetic naphthoquinone derivatives toward $K$. pneumoniae positive $\beta$-lactamase bacteria should be through break down the bacterial cell wall. ${ }^{30}$ Importantly, $K$. pneumoniae positive $\beta$-lactamase is a common intestinal bacteria that can cause life-threatening infections, as well as hospital-acquired infections, such as pneumonia. ${ }^{34,40}$ Overall, the synthetic amino naphthoquinones did not show better inhibition values than the commercial drug chloramphenicol. However, as NQA, NQC, and NQF showed good inhibition values against the bacteria tested, this is an indication that the three compounds mentioned are good scaffolds for the design of novel antibacterial drugs.

\section{Determination of binding parameters for HSA:naphthoquinone} derivatives

Among the synthetic naphthoquinones that showed the best antibacterial values (Table 1), the compounds NQA, NQC, and NQF were selected to study their interaction with HSA. The fluorescence properties of proteins result from the presence of aromatic amino acid residues such as phenylalanine (Phe), tyrosine (Tyr) and tryptophan (Trp). Although the fluorescence emission from HSA, at $\lambda_{\text {exc }}=280 \mathrm{~nm}$, has a weak contribution from the Phe and Tyr residues, ${ }^{26,41}$ the intrinsic fluorescence of HSA is mainly due to the Trp-214 residue. The effect of NQA on HSA fluorescence intensity is shown in Figure 2. After the successive addition of a solution of NQA to HSA (constant concentration, in PBS) a decrease in the fluorescence intensity of the protein is observed, indicating a possible interaction between albumin and the naphthoquinone. ${ }^{42}$ The naphthoquinones NQC and NQF followed the same trend and the results are shown in Figure S20 in the SI section.

The fluorescence quenching of HSA can occur mainly through two possible mechanisms: static or dynamic. The Stern-Volmer analysis is a good approximation to detect the main fluorescence quenching mechanism (inset of Figure 2 for NQA and inset of Figure S20 for NQC and NQF in the SI section). The values for the Stern-Volmer quenching constant $\left(\mathrm{K}_{\mathrm{SV}}\right)$ decrease with increasing temperature for all investigated naphthoquinone derivatives (Table 2). In addition, the bimolecular quenching rate constant $\left(\mathrm{k}_{\mathrm{q}}\right)$ values are about four orders of magnitude larger than the diffusion rate constant in water $\left(\mathrm{k}_{\mathrm{diff}}\right.$ ca. $7.40 \times 10^{9} \mathrm{M}^{-1} \mathrm{~s}^{-1}$, at $305 \mathrm{~K}$ according to Smoluchowski-Stokes-Einstein theory) ${ }^{43}$ (Table 2). Based on these results, it can be concluded that the main fluorescence quenching mechanism for HSA:NQA, HSA:NQC, and HSA:NQF is static, as a consequence of a ground-state association between the protein and each of the naphthoquinones under study. ${ }^{20,44}$ These results are in agreement with those

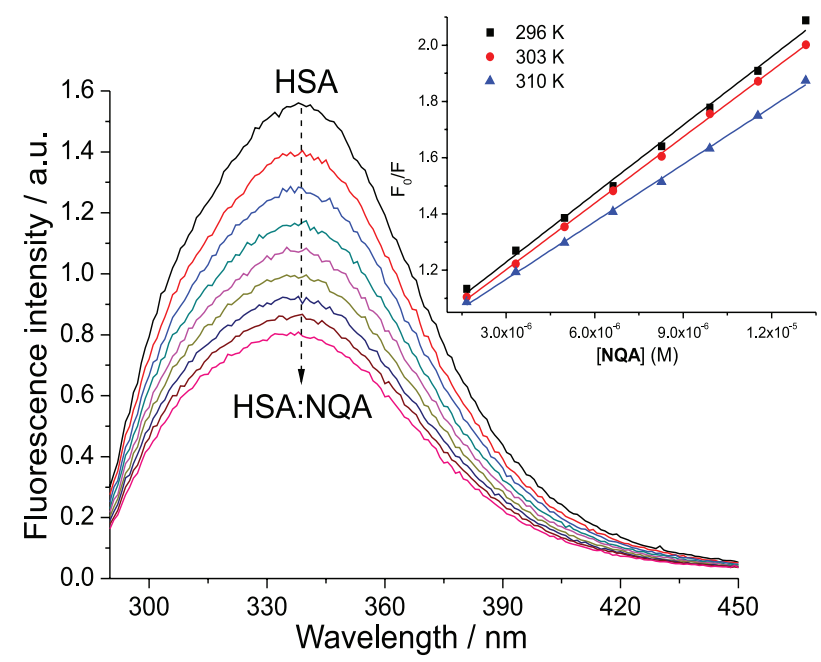

Figure 2. Steady-state fluorescence emission spectra for HSA in the absence and presence of successive additions of NQA at $\mathrm{pH}=7.4$ and $310 \mathrm{~K} .[\mathrm{HSA}]=1.00 \times 10^{-5} \mathrm{M},[\mathrm{NQA}]=0.17 ; 0.33 ; 0.50 ; 0.66 ; 0.83$; $0.99 ; 1.15$ and $1.32 \times 10^{-5} \mathrm{M}$. Inset: Stern-Volmer plots for HSA:NQA at 296,303 and $310 \mathrm{~K}$. 
Table 2. Binding parameters values $\left(\mathrm{K}_{\mathrm{SV}}, \mathrm{k}_{\mathrm{q}}, \mathrm{K}_{\mathrm{a}}, \Delta \mathrm{H}^{\circ}, \Delta \mathrm{S}^{\circ}\right.$ and $\left.\Delta \mathrm{G}^{\circ}\right)$ for the interaction HSA:NQA, HSA:NQC and HSA:NQF at 296, 303 and $310 \mathrm{~K}$

\begin{tabular}{|c|c|c|c|c|c|c|c|}
\hline Sample & $\mathrm{T} / \mathrm{K}$ & $\mathrm{K}_{\mathrm{SV}}\left(\times 10^{4}\right) / \mathrm{M}^{-1}$ & $\mathrm{k}_{\mathrm{q}}\left(\times 10^{13}\right) /\left(\mathrm{M}^{-1} \mathrm{~s}^{-1}\right)$ & $\mathrm{K}_{\mathrm{a}}\left(\times 10^{4}\right) / \mathrm{M}^{-1}$ & $\Delta \mathrm{H}^{\circ} /\left(\mathrm{kJ} \mathrm{mol}^{-1}\right)$ & $\Delta \mathrm{S}^{\circ} /\left(\mathrm{kJ} \mathrm{mol}^{-1} \mathrm{~K}^{-1}\right)$ & $\Delta \mathrm{G}^{\circ} /\left(\mathrm{kJ} \mathrm{mol}^{-1}\right)$ \\
\hline & 296 & $8.11 \pm 0.02$ & 1.37 & $8.98 \pm 0.26$ & & & -74.4 \\
\hline \multirow[t]{3}{*}{ HSA:NQA } & 303 & $7.86 \pm 0.07$ & 1.33 & $4.54 \pm 0.26$ & $-47.8 \pm 4.9$ & $0.0899 \pm 0.016$ & -75.0 \\
\hline & 310 & $6.81 \pm 0.09$ & 1.15 & $2.76 \pm 0.26$ & & & -75.7 \\
\hline & 296 & $7.82 \pm 0.02$ & 1.32 & $3.83 \pm 0.26$ & & & -37.2 \\
\hline \multirow[t]{3}{*}{ HSA:NQC } & 303 & $7.37 \pm 0.03$ & 1.25 & $2.88 \pm 0.26$ & $-31.6 \pm 0.9$ & $0.0189 \pm 0.0028$ & -37.3 \\
\hline & 310 & $7.15 \pm 0.02$ & 1.21 & $2.14 \pm 0.26$ & & & -37.4 \\
\hline & 296 & $7.98 \pm 0.02$ & 1.35 & $4.66 \pm 0.26$ & & & -49.2 \\
\hline \multirow[t]{2}{*}{ HSA:NQF } & 303 & $7.95 \pm 0.02$ & 1.34 & $3.25 \pm 0.26$ & $-37.8 \pm 0.3$ & $0.0384 \pm 0.0011$ & -49.4 \\
\hline & 310 & $7.86 \pm 0.02$ & 1.33 & $2.33 \pm 0.26$ & & & -49.7 \\
\hline
\end{tabular}

$\mathrm{r}^{2}$ for $\mathrm{K}_{\mathrm{SV}}$ and $\mathrm{k}_{\mathrm{q}}$ : 0.9994-0.9888; $\mathrm{r}^{2}$ for $\mathrm{K}_{\mathrm{a}}: 0.9998-0.9980 ; \mathrm{r}^{2}$ for $\Delta \mathrm{H}^{\circ}, \Delta \mathrm{S}^{\circ}$ and $\Delta \mathrm{G}^{\circ}$ : 0.9998-0.9887. HSA: human serum albumin; T: temperature; $\mathrm{K}_{\mathrm{sv}}$ : Stern-Volmer quenching constant; $\mathrm{k}_{\mathrm{q}}$ : bimolecular quenching rate constant; $\mathrm{K}_{\mathrm{a}}$ : modified Stern-Volmer binding constant; $\Delta \mathrm{H}^{\circ}$ : enthalpy; $\Delta \mathrm{S}^{\circ}$ : entropy; $\Delta \mathrm{G}^{\circ}$ : Gibbs free energy.

previously published for the interaction between HSA and some naphthoquinones, such as, for example juglone, ${ }^{42}$ plumbagin, ${ }^{45}$ and $\alpha$-pyran derivatives. ${ }^{46}$

Further confirmation that the main fluorescence quenching mechanism is static was obtained by timeresolved fluorescence measurements in the absence and in the presence of the maximum concentration of ligand used in steady-state fluorescence experiments $\left(1.32 \times 10^{-5} \mathrm{M}\right)$. According to Figure 3 and Table 3, time-resolved measurements indicated that fluorescence for free HSA, in PBS, at room temperature, has two distinct lifetimes with different contributions, i.e, $\tau_{1}=1.75 \pm 0.11 \mathrm{~ns}(25.0 \%$ contribution) and $\tau_{2}=5.90 \pm 0.10 \mathrm{~ns}$ ( $75.0 \%$ contribution). These results are in agreement with those found in the literature ${ }^{47}$ The fluorescence lifetimes for HSA without and in the presence of NQA, NQC, or NQF are the same in the experimental error, providing additional confirmation in favor of a static quenching process..$^{20,47}$

The evaluation of modified Stern-Volmer binding constant $\left(\mathrm{K}_{\mathrm{a}}\right)$ between serum albumin and a ligand is important for understanding the biodistribution of a potential drug in the plasma, body tissues, and organs. Too weak the binding can lead to a poor distribution of the molecule in the body, while a strong binding can decrease the concentration of free molecules in the bloodstream. ${ }^{48}$
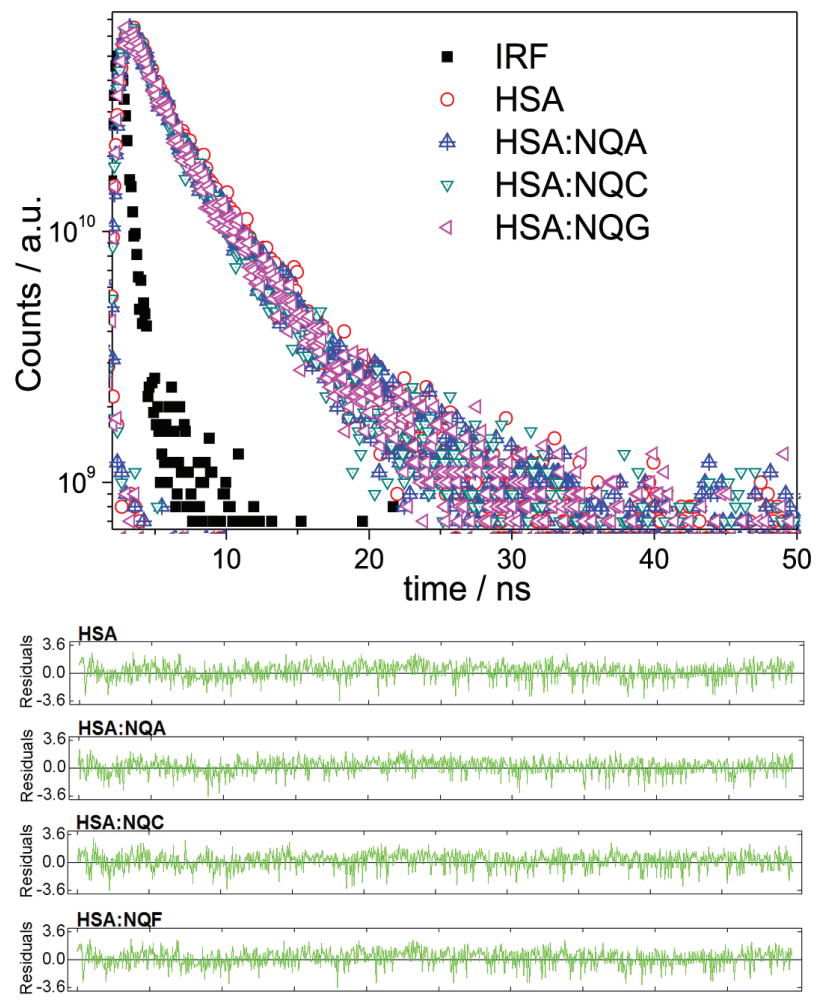

Figure 3. Time-resolved fluorescence decays and its residuals for HSA without and in the presence of NQA, NQC, or $\mathrm{NQF}$ at $\mathrm{pH}=7.4$ and room temperature. IRF: instrument response function (a mixture of $\mathrm{TiO}_{2}$, water, and glycerol).

Table 3. Time-resolved fluorescence parameters for HSA without and in the presence of NQA, NQC, and NQF at pH 7.4 and room temperature

\begin{tabular}{lccccc}
\hline Sample & $\tau_{1} / \mathrm{ns}$ & Relative $/ \%$ & $\tau_{2} / \mathrm{ns}$ & Relative $/ \%$ & $\chi^{2}$ \\
\hline HSA & $1.75 \pm 0.11$ & 25.0 & $5.90 \pm 0.10$ & 75.0 & 1.179 \\
HSA:NQA & $1.72 \pm 0.10$ & 22.5 & $5.86 \pm 0.11$ & 77.5 & 1.076 \\
HSA:NQC & $1.73 \pm 0.09$ & 23.4 & $5.87 \pm 0.10$ & 76.6 & 1.193 \\
HSA:NQF & $1.70 \pm 0.10$ & 23.0 & $5.84 \pm 0.09$ & 77.0 & 1.168 \\
\hline
\end{tabular}

$\tau_{1}$ : first fluorescence lifetime; $\tau_{2}$ : second fluorescence lifetime; $\chi^{2}$ : chi squared (measures the goodness of fit of experimental data to a bi-exponential decay); HSA: human serum albumin. 
Figure 4 shows the modified Stern-Volmer plots for HSA:NQA, at 296, 303, and $310 \mathrm{~K}$, while Figure S21 in the SI section shows similar plots for NQC and NQF. The $\mathrm{K}_{\mathrm{a}}$ values for the interaction HSA:naphthoquinones are of the order of $10^{4} \mathrm{M}^{-1}$ (Table 2), indicating a moderate binding affinity between the three potential antibacterial naphthoquinones and albumin, ${ }^{47,48}$ a result similar to that found for other 1,4-naphthoquinones, as for example, a synthetic derivative of pyran or a natural product such as $\alpha$-lapachone. ${ }^{46,49}$

Small molecules are usually bound to macromolecules through four binding modes: hydrogen bond, van der Waals forces, and electrostatic or hydrophobic interactions. Thermodynamic parameters, such as the enthalpy $\left(\Delta \mathrm{H}^{\circ}\right)$ and the entropy $\left(\Delta S^{\circ}\right)$ of a reaction are important for confirming the acting force on the binding process..$^{50}$ The temperatures chosen for determining the binding parameters were 298,303 and $310 \mathrm{~K}$ since at these temperatures HSA does not suffer any structural degradation. The thermodynamic parameters were obtained via the van't Hoff approximation (inset of the Figure 4 for NQA and of the Figure S21 in the SI section for NQC and NQF) and the results are shown in Table 2. The signal and magnitude of the thermodynamic parameters can be associated with the various individual interactions that are present in the association process between small molecules and proteins. ${ }^{51}$ An inspection of Table 2 shows that for the interaction $\mathrm{HSA}: \mathrm{NQA}, \mathrm{HSA}: \mathrm{NQC}$ and $\mathrm{HSA} \mathrm{NQF} \Delta \mathrm{H}^{\circ}$ have negative values, while the values for $\Delta S^{\circ}$ are positive. This indicates that hydrogen bonding and electrostatic forces play a key role in the albumin's ability to interact with these naphthoquinones. ${ }^{51}$ Furthermore, the negative sign for the Gibbs free energy $\left(\Delta \mathrm{G}^{\circ}\right)$ means that the interaction process

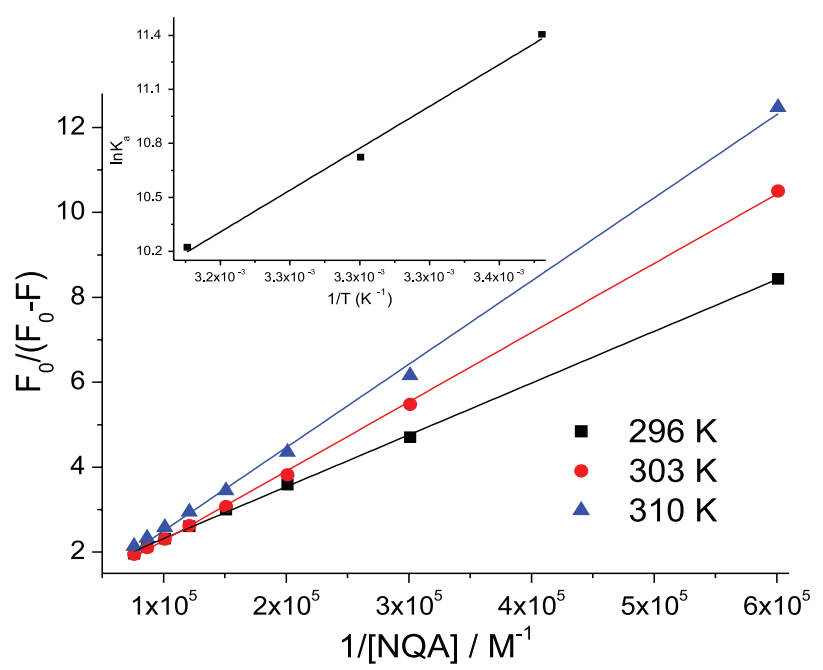

Figure 4. Modified Stern-Volmer plots for HSA:NQA at 296, 303, and $310 \mathrm{~K}$. Inset: van't Hoff plot for HSA:NQA. [HSA] $=1.00 \times 10^{-5} \mathrm{M}$ and $[\mathrm{NQA}]=0.17 ; 0.33 ; 0.50 ; 0.66 ; 0.83 ; 0.99 ; 1.15$ and $1.32 \times 10^{-5} \mathrm{M}$. is spontaneous, being both enthalpically $\left(\Delta \mathrm{H}^{\circ}<0\right)$ and entropically $\left(\Delta S^{\circ}<0\right)$ driven. ${ }^{29}$ These results show the same trend when compared to those for the interaction between HSA and some synthetic $\alpha$-pyran naphthoquinones, such as 2-phenyl-2,3-dihydronaphtho[2,3- $b$ ] furan-4,9-dione and 2-(4-bromophenyl)-2,3-dihydronaphtho[2,3-b]furan4,9-dione. ${ }^{46}$

Structural and microenvironmental perturbation on HSA structure upon ligand binding

Conformational changes in HSA as a function of the addition of synthetic naphthoquinones NQA, NQC, and NQF were evaluated using $\mathrm{CD}$ and SF techniques. In the far-UV CD spectrum of HSA, the appearance of two negative absorption bands (minima) at $208 \mathrm{~nm}$ $\left(\pi-\pi^{*}\right)$ and $222 \mathrm{~nm}\left(\mathrm{n}-\pi^{*}\right)$ (Figure 5) characterizes the presence of $\alpha$-helical content in the albumin structure. ${ }^{52}$ Figure 5 illustrates the CD spectra changes upon NQA binding to HSA in the far-UV region, whereas the results for NQC and NQF are shown in the Figure S22 of the SI section. The $\alpha$-helical content for HSA is about 65.9 and $61.3 \%$ at 208 and $222 \mathrm{~nm}$, respectively (Table 4). After the addition of the naphthoquinone derivative there was a decrease in the helical content of the albumin structure; however, this loss of ellipticity was very weak, showing a perturbation of $2.30 \%$ (at $208 \mathrm{~nm}$ ) and $2.20 \%$ (at $222 \mathrm{~nm}$ ) in the presence of NQA (Table 4). This is a clear indication that NQA can be accommodated inside the albumin structure without a significant perturbation of the secondary structure of the protein. The compounds NQC and NQF showed the same trend. In the literature, some synthetic naphthoquinone derivatives (2-phenyl-2,3-dihydronaphtho[2,3-b]furan-4,9-dione

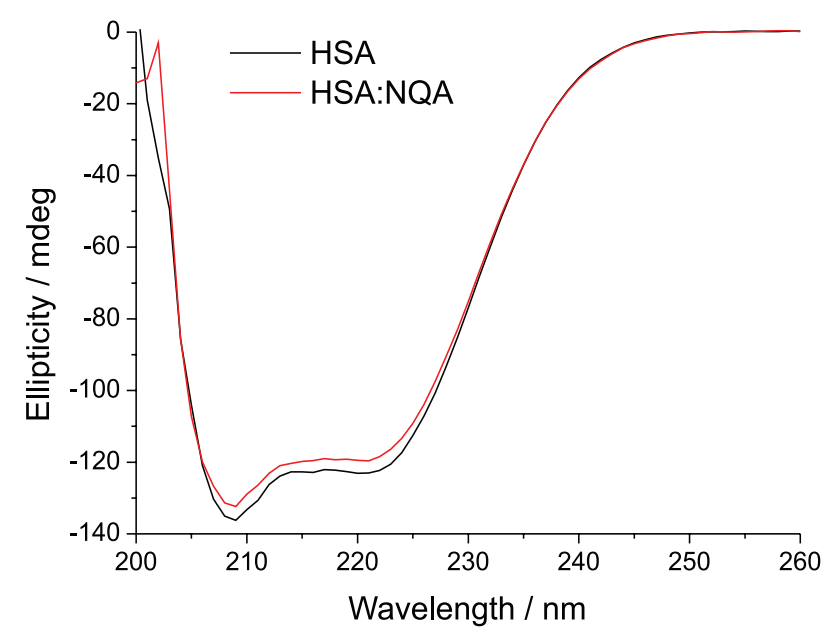

Figure 5. Circular dichroism spectra for HSA in the absence and in the presence of NQA at $310 \mathrm{~K}(\mathrm{pH}=7.4)$. [HSA] $=1.00 \times 10^{-6} \mathrm{M}$ and $[\mathrm{NQA}]=1.32 \times 10^{-5} \mathrm{M}$. 
Table 4. Quantitative $\alpha$-helix content for the interaction between HSA:NQA/NQC/NQF at $310 \mathrm{~K}$. $[\mathrm{NQA}]=[\mathrm{NQC}]=[\mathrm{NQF}]=1.32 \times 10^{-5} \mathrm{M}$

\begin{tabular}{lcccc}
\hline Sample & $\alpha$-helix $(208 \mathrm{~nm}) / \%$ & $\Delta_{208} \alpha$-helix $/ \%$ & $\alpha$-helix $(222 \mathrm{~nm}) / \%$ & $\Delta_{222} \alpha$-helix $/ \%$ \\
\hline HSA & 65.9 & - & 61.3 & - \\
HSA:NQA & 63.6 & 2.30 & 59.1 & 2.20 \\
HSA:NQC & 65.5 & 0.40 & 59.4 & 1.90 \\
HSA:NQF & 64.1 & 1.80 & 59.3 & 2.00 \\
\hline
\end{tabular}

HSA: human serum albumin.

and 2-(4-bromophenyl)-2,3-dihydronaphtho[2,3-b]furan4,9-dione) also did not perturb significantly the secondary structure of albumin. ${ }^{46}$

In SF emission spectroscopy, characteristic information on tyrosine or tryptophan residues can be obtained when the $\Delta \lambda$ between the excitation and emission wavelengths is set at 15 or $60 \mathrm{~nm}$, respectively. ${ }^{50}$ The SF spectra resulting from the interaction between NQA and HSA are presented in Figure 6, while Figure S23 in the SI section shows SF spectra for HSA:NQC and HSA:NQF. These spectra clearly show that the fluorescence intensity of HSA decreases regularly along with the addition of naphthoquinones NQA, NQC, and NQF, further demonstrating the occurrence of fluorescence quenching in the binding process. Moreover, there was no significant shift in the maximum emission wavelength with $\Delta \lambda=15 \mathrm{~nm}$, implying that the interaction of these naphthoquinones with HSA does not affect the microenvironment around Tyr residues. ${ }^{53}$ On the other hand, when $\Delta \lambda=60 \mathrm{~nm}$, the addition of NQA, NQC, and $\mathrm{NQF}$ to the albumin solution led to a slight red shift of the HSA signal (from 280 to 283; 288; and $288 \mathrm{~nm}$ for NQA, NQC, and NQF, respectively), indicating that they can perturb the microenvironment around the Trp-214 residue by increasing the polarity around this main albumin fluorophore. ${ }^{54,55}$

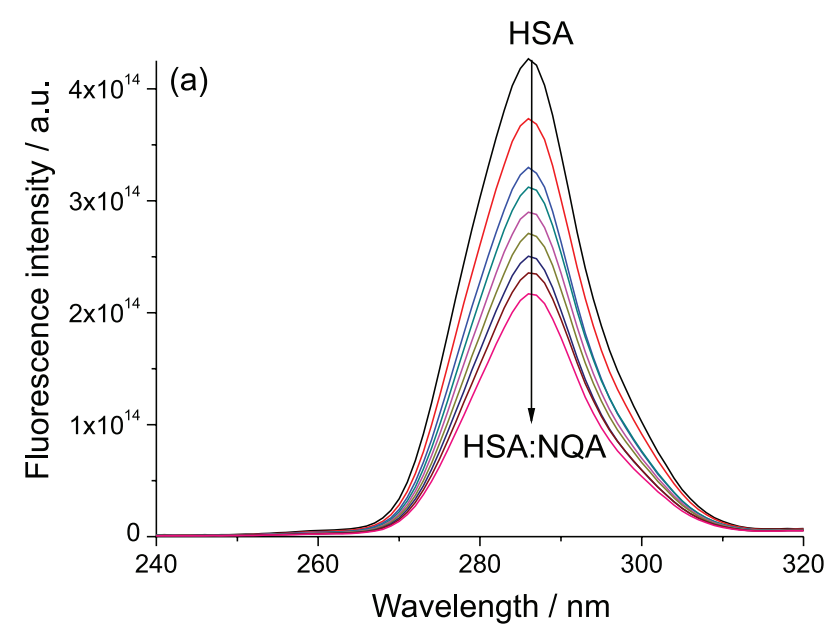

Competitive binding studies and molecular docking analysis

The HSA framework has two major binding sites for organic compounds, known as Sudlow's sites I and II. ${ }^{19}$ In order to determine which major binding site was involved during the interaction process between HSA and the naphthoquinones NQA, NQC, and NQF, competitive drug displacement experiments were performed using warfarin (site I, located in subdomain IIA) and ibuprofen (site II, located in subdomain IIIA) as marker sites.

The HSA structure has two main binding sites for organic compounds, known as Sudlow's site I and II. ${ }^{19}$ In order to determine which major binding site was involved in the interaction process between HSA and the naphthoquinones NQA, NQC, and NQF, competitive drug displacement experiments were performed using warfarin (site I, located in subdomain IIA) and ibuprofen (site II, located in subdomain IIIA) as marker sites. Figure S24 in the SI section depicts modified Stern-Volmer plots for the interaction HSA:NQA, HSA:NQC and HSA:NQF in the presence of warfarin or ibuprofen, at $296 \mathrm{~K}$. The $\mathrm{K}_{\mathrm{a}}$ values in the presence of warfarin were $(7.61 \pm 0.15)$, $(3.18 \pm 0.19)$, and $(3.89 \pm 0.19) \times 10^{4} \mathrm{M}^{-1}$ for NQA, NQC, and NQF, respectively. On the other hand, when in the presence of ibuprofen $\mathrm{K}_{\mathrm{a}}$ values of $(8.59 \pm 0.14)$, $(3.73 \pm 0.21)$, and $(4.61 \pm 0.17) \times 10^{4} \mathrm{M}^{-1}$ were obtained for

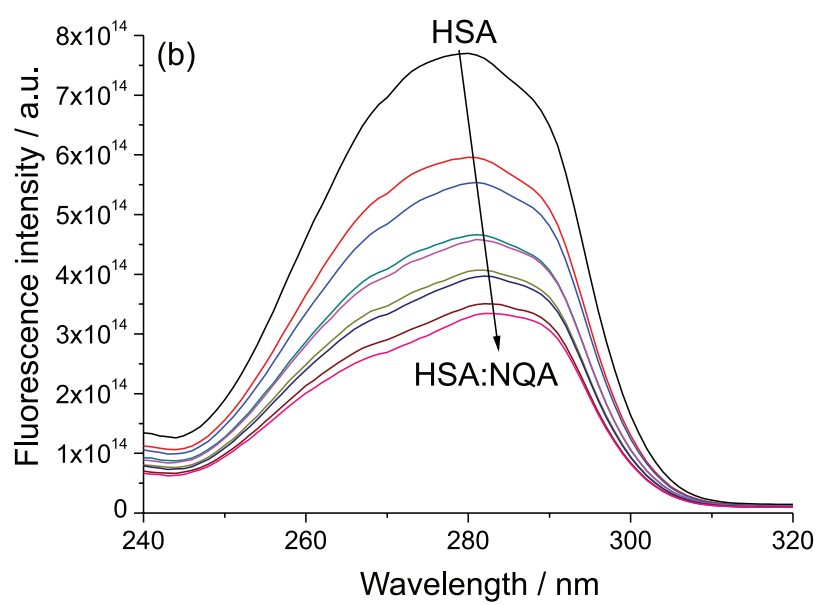

Figure 6. SF spectra for HSA without and in the presence of successive additions of NQA at (a) $\Delta \lambda=15 \mathrm{~nm}$ (tyrosine) and (b) $\Delta \lambda=60 \mathrm{~nm}$ (tryptophan). $[\mathrm{HSA}]=1.00 \times 10^{-5} \mathrm{M}$ and $[\mathrm{NQA}]=0.17 ; 0.33 ; 0.50 ; 0.66 ; 0.83 ; 0.99 ; 1.15$ and $1.32 \times 10^{-5} \mathrm{M}$. 
NQA, NQC, and NQF, respectively. A comparison of the $\mathrm{K}_{\mathrm{a}}$ values obtained for these synthetic naphthoquinones in the absence of local markers at $296 \mathrm{~K}$ (Table 2) with those obtained in the presence of either warfarin or ibuprofen shows that the binding constant $\mathrm{K}_{\mathrm{a}}$ in the presence of warfarin decreased by about $15.3,17.0$ and $16.5 \%$ for NQA, NQC, and NQF, respectively, remaining unchanged in the presence of ibuprofen. These results are clear evidence that these synthetic naphthoquinones compete with warfarin for the same local binding. Thus, it can be concluded that Sudlow's site I (subdomain IIA) is the primary binding pocket for NQA, NQC, and NQF. ${ }^{20,54}$

Since experimental results indicated site $\mathrm{I}$ as the main protein's binding pocket for NQA, NQC, and NQF, molecular docking calculations were carried out to offer a molecular level explanation on the binding ability between HSA:naphthoquinones. Figure 7 depicts the best docking pose for each ligand inside subdomain IIA and Table 5 shows the main amino acid residues which can interact to each ligand, as well as its distance and type of intermolecular force.

Molecular docking results suggested that NQC and NQF have a quite similar docking pose (Figure 7a), explaining the similarity in the binding constant values (Table 2), while NQA presented a different pose. Theoretical calculations suggested hydrogen bonding and van der Waals forces as the main type of intermolecular interaction for all ligands and amino acid residues in the subdomain IIA. It is important to note that the same intermolecular forces were also suggested experimentally (see thermodynamic parameters discussion). As an example, the hydrogen from $-\mathrm{NH}^{3+}$ and $-\mathrm{NH}$ group of Lys-194 and Trp-214 residues, respectively, can interact with the oxygens from the 1,4-naphthoquinone moiety of the compound NQA within a distance of 3.50 and $3.40 \AA$, respectively. On the other hand, the amino acid residues Lys-197, Val-342, Leu-452, Leu-456, and Leu-480 can interact with NQA structure via van der Waals forces, within a distance of 2.60, 3.20, 2.90, 1.30 , and $1.90 \AA$, respectively.

\section{Conclusions}

Six amino-naphthoquinone derivatives (NQA-NQF) were synthesized with satisfactory yields (40-71\%). The structure of each synthetic compound was determined according to the melting point, elemental analysis, FTIR and NMR analysis $\left({ }^{1} \mathrm{H}\right.$ and $\left.{ }^{13} \mathrm{C}\right)$. The synthetic compound NQA was the most active naphthoquinone against two Gram-positive bacteria ( $S$. aureus and B. cereus) with MIC values of $31.2 \mu \mathrm{g} \mathrm{mL}^{-1}$, in both cases. The NQF compound was the most active amino-naphthoquinone derivative ( $\mathrm{MIC}=31.2 \mu \mathrm{g} \mathrm{mL} \mathrm{m}^{-1}$ ) against gram-negative $K$. pneumoniae positive $\beta$-lactamase (a common intestinal bacterium that can cause life-threatening infections).
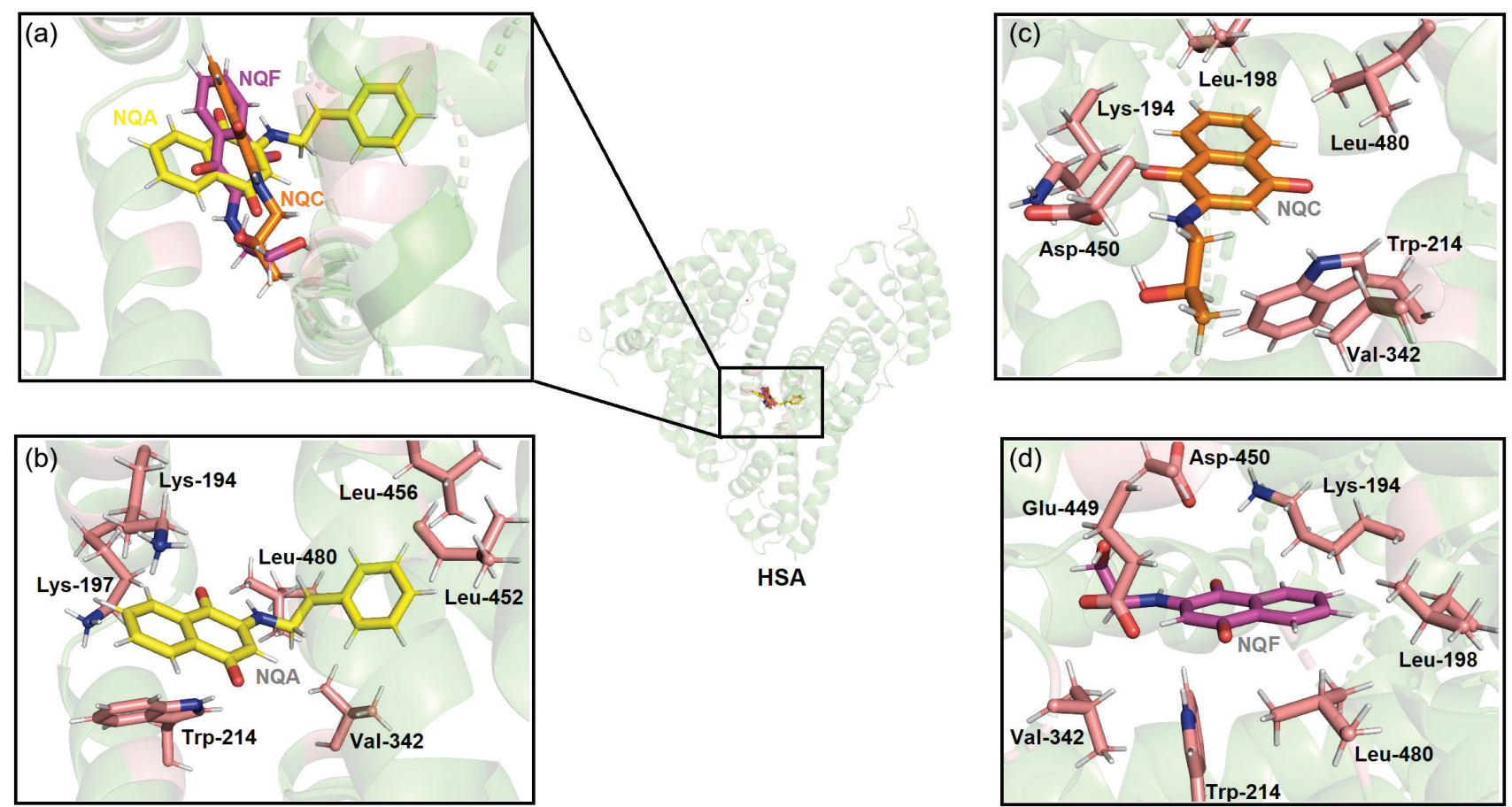

Figure 7. (a) Superposition of the best docking pose for all ligands under study inside subdomain IIA (ChemPLP function). Representation of the best molecular docking result for the interaction (b) HSA:NQA, (c) HSA:NQC, and (d) HSA:NQF. HSA structure is represented as cartoon in green, selected amino acid residues, NQA, NQC, and NQF are represented as sticks in beige, yellow, orange, and purple, respectively. Elements' colors: hydrogen, oxygen and nitrogen are represented in white, red and blue, respectively. 
Table 5. Molecular docking results for the interaction HSA and NQA, NQC and NQF in the site I

\begin{tabular}{lccc}
\hline Sample & $\begin{array}{c}\text { Amino acid } \\
\text { residue }\end{array}$ & Interaction & Distance / \\
\hline \multirow{4}{*}{ HSA:NQA } & Lys-194 & hydrogen bonding & 3.50 \\
& Lys-197 & van der Waals & 2.60 \\
& Trp-214 & hydrogen bonding & 3.40 \\
& Val-342 & van der Waals & 3.20 \\
& Leu-452 & van der Waals & 2.90 \\
& Leu-456 & van der Waals & 1.30 \\
& Leu-480 & van der Waals & 1.90 \\
\hline HSA:NQC & Lys-194 & van der Waals & 2.90 \\
& Leu-198 & van der Waals & 1.80 \\
& Trp-214 & hydrogen bonding & 2.20 \\
& Val-342 & van der Waals & 2.80 \\
& Asp-450 & van der Waals & 2.00 \\
& Leu-480 & van der Waals & 1.80 \\
\hline HSA:NQF & Lys-194 & hydrogen bonding & 3.60 \\
& Leu-198 & van der Waals & 2.40 \\
& Trp-214 & van der Waals & 3.20 \\
& Glu-449 & van der Waals & 2.50 \\
& Asp-450 & hydrogen bonding & 2.00 \\
& Leu-480 & van der Waals & 2.00 \\
\hline
\end{tabular}

HSA: human serum albumin; Lys: lysine; Trp: tryptophan; Val: valine; Leu: leucine; Asp: aspartic acid; Glu: glutamic acid.

Overall, NQA, NQC and NQF showed good profile as potential antibiotics, being more active than some other synthetic naphthoquinones described in the literature (for example, 5-amino-8-hydroxy-1,4-naphthoquinone). For the three most active compounds (NQA, NQC and $\mathrm{NQF}$ ), the interaction with HSA showed good binding capacity. Both naphthoquinones can interact with the Sudlow I site (subdomain IIA) of the protein through a ground state association. The interaction is moderate, thermodynamically favorable and does not significantly disturb the secondary structure of the protein. The hydrogen and van der Waals binding forces are the main intermolecular interactions between each compound and the amino acid residues present in the HSA binding bag.

\section{Supplementary Information}

The supplementary information (UV-Vis spectra for NQA, NQC and NQF in PBS solution; all spectra for the characterization of the synthetic compounds NQA-NQF; steady-state fluorescence emission spectra and SternVolmer plots for HSA:NQC/NQF; modified Stern-Volmer and van't Hoff plots for the interaction HSA:NQC/NQF at three different temperatures; circular dichroism spectra for HSA:NQC/NQF at $310 \mathrm{~K}$; SF spectra for HSA:NQC/NQF at $\Delta \lambda=15$ and $60 \mathrm{~nm}$; modified Stern-Volmer plots for $\mathrm{HSA}: \mathrm{NQA} / \mathrm{NQC} / \mathrm{NQF}$ in the presence of warfarin and ibuprofen at $310 \mathrm{~K}$ ) is available free of charge at http://jbcs.sbq.org.br as PDF file.

\section{Acknowledgments}

This research was funded by the Brazilian agencies: Coordenação de Aperfeiçoamento de Pessoal de Nível Superior (CAPES), Conselho Nacional de Desenvolvimento Científico e Tecnológico (CNPq), and Fundação de Amparo à Pesquisa do Estado do Rio de Janeiro (FAPERJ). A special acknowledgement is given to Prof Dr Carlos M. R. Sant'Anna from Laboratório de Modelagem Molecular (Institute of Chemistry at UFRRJ, Brazil) for the molecular docking facilities, to Prof Dr Nanci Câmara de Lucas Garden (Institute of Chemistry at UFRJ, Brazil) for the time-resolved and synchronous fluorescence facilities and Laboratory of Environmental Science of the Universidade Estadual do Norte Fluminense (UENF, Brazil) for the elemental analyses. J.C.N.-F. thanks the Instituto Nacional de Metrologia, Qualidade e Tecnologia (INMETRO, Brazil) for a Visiting Professor fellowship.

\section{Author Contributions}

O.A.C., J.C.N.-F. and A.E. conceptualization of the research; C.C.S. and A.E. synthesis and characterization of the naphthoquinone derivatives; R.O.P. and G.L.C. conducted the biological assays (antibacterial assays); O.A.C. and J.C.N.-F. conducted the HSA binding studies (spectroscopic and theoretical analysis). All authors contributed for the written of the manuscript.

\section{References}

1. Delarmelina, M.; Daltoé, R. D.; Cerri, M. F.; Madeira, K. P.; Rangel, L. B. A.; Lacerda Jr., V.; Romão, W.; Taranto, A. G.; Greco, S. J.; J. Braz. Chem. Soc. 2015, 26, 1804.

2. Wang, S. H.; Lo, C. Y.; Gwo, Z. H.; Lin, H. J.; Chen, L. J.; Cuo, C. D.; Vu, J. W.; Molecules 2015, 20, 11994.

3. Janeczko, M.; Demchuk, O. M.; Strzelecka, D.; Kubinski, K.; Masiyk, M.; Eur. J. Med. Chem. 2016, 124, 1019.

4. Sreelatha, T.; Kandhasamy, S.; Dinesh, R.; Shruthy, S.; Shweta, S.; Mukesh, D.; Karunagaran, D.; Balaji, R.; Mathivanan, N.; Perumal, P. T.; Bioorg. Med. Chem. Lett. 2014, 24, 3647.

5. Rahmoun, N. M.; Boucherit-Otmani, Z.; Benabdallah, M.; Choukchou-Braham, N.; Med. Mal. Infect. 2012, 42, 270. 
6. Soares, A. S.; Barbosa, F. L.; Rüdiger, A. L.; Hughes, D. L.; Salvador, M. J.; Zampronio, A. R.; Stefanello, M. E. A.; J. Nat. Prod. 2017, 80, 1837.

7. Klotz, L. O.; Hou, X.; Jacob, C.; Molecules 2014, 19, 14902.

8. Pardee, A.; Li, Y.; Li, C.; Curr. Cancer Drug Targets 2002, 2 , 227; Valderrama, A. J.; Leiva, H.; Rodriguez, J. Á.; Theoduloz, C.; Schmeda-Hirshmann, G.; Bioorg. Med. Chem. 2008, 16, 3687.

9. Ferreira, M. P. S. B. C.; Cardoso, M. F. C.; Silva, F. C.; Ferreira, V. F.; Lima, E. S.; Souza, J. B. V.; Ann. Clin. Microbiol. Antimicrob. 2014, 13, 26.

10. Sánchez-Calvo, J. M.; Barbero, G. R.; Guerrero-Vásquez, G.; Durán, A. G.; Macías, M.; Rodríguez-Iglesias, M. A.; Molinillo, J. M. G.; Macías, F. A.; Med. Chem. Res. 2016, 25, 1274.

11. Emori, T. G.; Gaynes, R. P.; Clin. Microbiol. Rev. 1993, 6, 428.

12. Kresken, M.; Wiedemann, B.; Antimicrob. Agents Chemother. 1988, 32, 1285.

13. Bhavnani, S. M.; Ballow, C. H.; Curr. Opin. Microbiol. 2000, 3,528 .

14. Novais, J. S.; Moreira, C. S.; Silva, A. C. J. A.; Loureiro, R. S.; Figueiredo, A. M. S.; Ferreira, V. F.; Castro, H. C.; Rocha, D. R.; Microb. Pathog. 2018, 118, 105.

15. Fasano, M.; Curry, S.; Terreno, E.; Galliano, M.; Fanali, G.; Narciso, P.; Notari, S.; Ascenzi, P.; IUBMB Life 2005, 57, 787.

16. He, X. M.; Carter, D. C.; Nature 1992, 358, 209.

17. Otagiri, M.; Drug Metab. Pharmacokinet. 2005, 20, 309.

18. Wardell, M.; Wang, Z.; Ho, J. X.; Robert, J.; Ruker, F.; Ruble, J.; Carter, D. C.; Biochem. Biophys. Res. Commun. 2002, 291, 813.

19. Sudlow, G.; Birkett, D. J.; Wade, D. N.; Mol. Pharmacol. 1976, $12,1052$.

20. Chaves, O. A.; Oliveira, C. H. C. S.; Ferreira, R. C.; Melos, J. L. R.; Rodrigues-Santos, C. E.; Echevarria, A.; Cesarin-Sobrinho, D.; J. Fluorine Chem. 2017, 199, 103.

21. Cunha, S.; Santos, L. F. P.; Rocha, Z. N.; Rivelino, R.; Ferrari, J.; Vencato, I.; Lariucci, C.; Quim. Nova 2010, 33, 2108.

22. Fieser, L. F.; Berliner, E.; Bondhus, F. J.; Chang, F. C.; Dauben, W. G.; Ettlinger, M. G.; Fawaz, G.; Fields, M.; Heidelberger, C.; Heymann, H.; Vaughan, W. R.; Wilson, A. G.; Wilson, E.; Wu, M.; Hamlin, K. E.; Matson, E. J.; Moore, E. E.; Moore, M. B.; Zaugg, H. E.; J. Am. Chem. Soc. 1948, 70, 3174.

23. National Committee for Clinical Laboratory Standards; Methods for Dilution Antimicrobial Susceptibility Tests for Bacteria that Grow Aerobically, $6^{\text {th }}$ ed.; Approved Standard NCCLS Document M7-A6: Wayne, PA, 2003.

24. Balouiri, M.; Sadiki, M.; Ibnsouda, S. K.; J. Pharm. Anal. 2016, 6,71 .

25. Chaves, O. A.; Jesus, C. S. H.; Cruz, P. F.; Sant'Anna, C. M. R.; Brito, R. M. M.; Serpa, C.; Spectrochim. Acta, Part A 2016, 169, 175.
26. Lakowicz, J. R.; Principles of Fluorescence Spectroscopy, $3^{\text {rd }}$ ed.; Springer: New York, USA, 2006.

27. Chaves, O. A.; Santos, M. R. L.; de Oliveira, M. C. C.; Sant'Anna, C. M. R.; Ferreira, R. C.; Echevarria, A.; NettoFerreira, J. C.; J. Mol. Liq. 2018, 254, 280.

28. Chaves, O. A.; de Barros, L. S.; de Oliveira, M. C. C.; Sant'Anna, C. M. R.; Ferreira, A. B. B.; da Silva, F. A.; CesarinSobrinho, D.; Netto-Ferreira, J. C.; J. Fluorine Chem. 2017, 199, 30.

29. Spartan'14; Wavefunction Inc., Irvine, USA, 2014.

30. http://www.ccdc.cam.ac.uk/solutions/csd-discovery/ components/gold/, accessed in March 2020.

31. DeLano, W. L.; PyMOL User's Guide; DeLano Scientific LLC, San Carlos, CA, USA, 2002.

32. Chaves, O. A.; Mathew, B.; Joy, M.; Lohidakshan, K. K.; Marathakam, A.; Netto-Ferreira, J. C.; J. Mol. Liq. 2018, 260, 186.

33. Ramos-Peralta, L.; López-López, L. I.; Silva-Belmares, S. Y.; Zugasti-Cruz, A.; Rodriguez-Herrera, R.; Aguilar-González, C. N. In Naphthoquinone: Bioactivity and Green Synthesis, The Battle Against Microbial Pathogens: Basic Science; Méndez-Vilas, A., ed.; Technological Advances and Educational Programs: Seattle, 2015, p. 556-564.

34. World Health Organization (WHO); https://www.who.int/newsroom/fact-sheets/detail/antibiotic-resistance, accessed in March 2020.

35. Spellberg, B.; Guidos, R.; Gilbert, D.; Bradley, J.; Boucher, H. W.; Scheld, W. M.; Bartlett, J. G.; Edwards, J. J.; Clin. Infect. Dis. 2008, 46, 155.

36. Machado, T. B.; Pinto, A. V.; Pinto, M. C. F.; Leal, I. C. R.; Silva, M. G.; Amaral, A. C. F.; Kuster, R. M.; Netto-dos-Santos, K. R.; Int. J. Antimicrob. Agents 2003, 21, 279.

37. Tandon, V. K.; Yadav, D. B.; Singh, R. V.; Vaish, M.; Chaturvedi, A. K.; Shukla, P. K.; Bioorg. Med. Chem. Lett. 2005, 15, 3463.

38. Brandelli, A.; Bizani, D.; Martinelli, M.; Stefani, V.; Gerbase, A. E.; Rev. Bras. Cienc. Farm. 2004, 40, 247.

39. Riffel, A.; Medina, L. F.; Stefani, V.; Santos, R. C.; Bizani, D.; Brandelli, A.; Braz. J. Med. Biol. Res. 2002, 35, 811.

40. Tragante, C. R.; Ceccon, M. E. J. R.; Falcão, M. C.; Seiti, M.; Sakita, N.; Vieira, R. A.; Rev. Paul. Pediatr. 2008, 26, 59.

41. Sułkowska, A.; J. Mol. Struct. 2002, 614, 227.

42. Jahanban-Esfahlan, A.; Davaran, S.; Moosavi-Movahedi, A. A.; Dastmalchi, S.; J. Iran. Chem. Soc. 2017, 14, 1527.

43. Montalti, M.; Credi, A.; Prodi, L.; Gandolfi, M. T.; Handbook of Photochemistry, $3^{\text {rd }}$ ed.; CRC Press, Taylor \& Francis: Boca Raton, 2006.

44. Chaves, O. A.; Mathew, B.; Cesarin-Sobrinho, D.; Lakshminarayanan, B.; Joy, M.; Mathew, G. E.; Suresh, J.; Netto-Ferreira, J. C.; J. Mol. Liq. 2017, 242, 1018.

45. Li, S.; Yao, D.; Bian, H.; Chen, Z.; Yu, J.; Yu, Q.; Liang, H.; J. Solution Chem. 2011, 40, 709. 
46. Ferreira, R. C.; Chaves, O. A.; de Oliveira, C. H. C. S.; Ferreira, S. B.; Ferreira, V. F.; Sant'Anna, C. M. R.; Cesarin-Sobrinho, D.; Netto-Ferreira, J. C.; Rev. Virtual Quim. 2018, 10, 432.

47. Sun, H.; Liu, Y.; Li, M.; Han, S.; Yang, X.; Liu, R.; Luminescence 2016, 31, 335.

48. Naveenraj, S.; Anandan, S.; J. Photochem. Photobiol., C 2013, $14,53$.

49. Chaves, O. A.; Schaeffer, E.; Sant'Anna, C. M. R.; Netto-Ferreira, J. C.; Cesarin-Sobrinho, D.; Ferreira, A. B. B.; Mediterr. J. Chem. 2016, 5, 331.

50. Yang, G. D.; Li, C.; Zeng, A. G.; Zhang, Y.; Yang, R.; Bian, X.-L.; J. Pharm. Anal. 2013, 3, 200.
51. Ross, P. D.; Subramanian, S.; Biochemistry 1981, $20,3096$.

52. Baig, M. H.; Rahman, S.; Rabbani, G.; Imran, M.; Ahmad, K.; Choi, I.; Int. J. Mol. Sci. 2019, 20, 662.

53. Cui, S. Y.; Hu, X. L.; Liu, J. Q.; J. Solution Chem. 2011, 40, 764.

54. Tan, H.; Chen, L.; Ma, L.; Liu, S.; Zhou, H.; Zhang, Y.; Guo, T.; Liu, W.; Dai, H.; Yu, Y.; Toxins 2019, 11, 214.

55. Byadagi, K.; Meti, M.; Nandibewoor, S.; Chimatadar, S.; J. Pharm. Anal. 2017, 7, 103.

Submitted: January 5, 2020 Published online: April 16, 2020 